\title{
INTERthesis
}

DOUTORADO INTERDISCIPLINAR EM CIÊNCIAS HUMANAS - UFSC - FLORIANÓPOLIS - SC - BRASIL

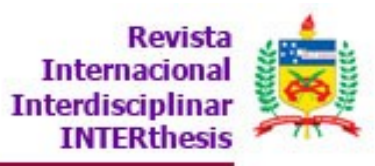

INTERthesis

\section{EFEITOS DA COBERTURA PREVIDENCIÁRIA NA SITUAÇÃO DE VIDA DE IDOSOS RURAIS DE SANTANA DA BOA VISTA - RIO GRANDE DO SUL}

\section{EFFECTS OF THE SOCIAL WELFARE ON THE LIFE SITUATION OF THE ELDERLY IN THE RURAL AREA OF SANTANA DA BOA VISTA - RIO GRANDE DO SUL}

\section{LOS EFECTOS DE LA SEGURIDAD SOCIAL EN LA SITUACIÓN DE VIDA DE LAS PERSONAS DE MAYOR EDAD EN EL MEDIO RURAL DE SANTANA DA BOA VISTA - RIO GRANDE DO SUL}

\author{
Cristiane Tonezer ${ }^{1}$ \\ Marta Júlia Marques Lopes ${ }^{2}$
}

\section{RESUMO:}

Este estudo analisa as mudanças ocorridas na situação de vida da população de idosos rurais de Santana da Boa Vista - Rio Grande do Sul, a partir do acesso aos benefícios previdenciários. Insere-se em um Programa Interdisciplinar de Pesquisa que busca integrar enfoques multidisciplinares na análise do desenvolvimento rural em regiões do Estado do Rio Grande do Sul, mais especificamente a chamada Metade Sul. O objetivo é descrever e analisar, mudanças ocorridas na situação de vida dos idosos rurais após a cobertura previdenciária. Trata-se de um estudo exploratório e descritivo com coleta e análise qualitativa de dados obtidos por meio de entrevista, com 30 idosos beneficiários da Previdência Social, residentes no meio rural do Município estudado. Observou-se, que os benefícios previdenciários proporcionaram diminuição da sua "carga" de trabalho, pela regularidade do aporte mensal, permitiu que continuassem morando no meio rural, lugar do qual não cogitam sair e, principalmente, maior poder no sentido de autonomia e independência nas relações familiares, auxiliando filhos e netos, com os quais planejam o futuro e elaboram diferentes estratégias para se manterem no meio rural.

Palavras-chave: Idosos rurais. Benefícios previdenciários. Situação de vida. Família.

\section{ABSTRACT:}

This study analyzes the changes which occurred in the life situation of the old population of the rural area of Santana da Boa Vista, Rio Grande do Sul, with the social welfare benefits. The study is part of an Interdisciplinary Research Program that aims at integrating multidisciplinary focuses on the analysis of the rural development in areas of the state of Rio Grande do Sul, more precisely in the region known as Metade Sul. The objective is to describe and analyze the changes occurred in the situation of life of the

\footnotetext{
${ }^{1}$ Mestre em Desenvolvimento Rural pela Universidade Federal do Rio Grande do Sul, 2009. Bacharel em Desenvolvimento Rural e Gestão Agroindustrial pela Universidade Estadual do Rio Grande do Sul, 2005. Email: cristianetonezer@yahoo.com.br

${ }^{2}$ Professora titular em saúde coletiva da Escola de Enfermagem da Universidade Federal do Rio Grande do Sul. Doutora e Mestre em Sociologia pela Université de Paris, França. E-mail: $\underline{\text { marta@enf.ufrgs.br }}$
}

R. Inter. Interdisc. INTERthesis, Florianópolis, v.6, n.2, p. 191-209, jul./dez. 2009 
elderly and if they have benefitted from the help of the social welfare. Therefore, it is an exploratory and descriptive study with data collection and qualitative data analysis by means of interviews with 30 senior citizens, Social welfare beneficiaries, residents in the rural environment of the town studied. It was observed that the social welfare benefits have allowed them to diminish their workload because of the regularity of the monthly contribution, has guaranteed the continuation of their life in the rural environment, a place which they do not consider leaving, and, mainly, has given them larger power in the sense of autonomy and independence in the family relationships, since they can help their children and grandchildren, with whom they not only plan the future, but also elaborate different strategies to remain in the rural environment.

Keywords: Elderly in rural areas. Social welfare benefits. Living situation. Family.

\section{RESUMEN:}

Este estudio analiza los cambios ocurridos en la situación de vida de las personas de mayor edad en el medio rural de Santana da Boa Vista - Rio Grande do Sul, después del acceso a los beneficios de la seguridad social. Se inserta en un Programa Interdisciplinario de Investigación que busca integrar enfoques multidisciplinarios en el análisis del desarrollo rural en regiones del Estado do Rio Grande do Sul, más específicamente en la llamada Mitad Sur. El objetivo es describir y analizar los cambios que ocurrieron en la situación de vida de esas personas después que recibieron el beneficio de la seguridad social. Se trata de un estudio exploratorio y descriptivo con recolección de información y análisis de tipo cualitativo de los datos a través de entrevista, con 30 personas de mayor edad, residentes en el medio rural del Municipio estudiado, beneficiados por la Seguridad Social. Se observó que los beneficios de la seguridad social les proporcionan una reducción en su "carga" de trabajo, por la regularidad del aporte mensual, permite que puedan continuar viviendo en el campo, donde ellos no piensan en salir y, principalmente, un mayor poder en el sentido de autonomía e independencia en las relaciones familiares, pudiendo ayudar a los hijos y nietos, con quienes planean el futuro y elaboran diferentes estrategias para permanecieren en el ambiente rural.

Palabras-clave: Personas de mayor edad en ambiente rural. Beneficios de la seguridad social. Situación de vida. Familia.

\section{INTRODUÇÃO}

O presente estudo foi elaborado a partir da dissertação de mestrado da primeira autora intitulada: Idosos rurais de Santana da Boa Vista - Rio Grande do Sul: efeitos da cobertura previdenciária, que objetivou discutir e analisar mudanças ocorridas na situação de vida da população de idosos rurais a partir do acesso aos benefícios previdenciários. Insere-se em um programa intitulado Programa Interdisciplinar de Pesquisa (PROINTER) o qual tem por objetivo, integrar enfoques interdisciplinares na análise do desenvolvimento rural, ou seja, discutir as relações dos sistemas naturais e sociais, contribuir com reflexões para a formulação de novas concepções de desenvolvimento rural, contribuir com propostas de planos de ação ou políticas de desenvolvimento que

R. Inter. Interdisc. INTERthesis, Florianópolis, v.6, n.2, p. 191-209, jul./dez. 2009 
levem em consideração as condições de reprodução dos sistemas naturais e sociais das populações e fortalecer laços cooperativos entre pesquisa e a ação para o desenvolvimento regional, estabelecendo mecanismos de colaboração entre pesquisadores, serviços e os diferentes atores sociais. A temática central do Programa é o desenvolvimento rural em regiões do Estado do Rio Grande do Sul, mais especificamente a chamada Metade $\mathrm{Sul}^{3}$, uma região social e economicamente marginalizada que sofre crescente desaceleração econômica, com reflexos sociais importantes, quando comparada a outras regiões do Estado (UFRGS, 2005).

Devido à extensão da área citada os estudos propostos pelo programa foram focados, primeiramente, em oito municípios: Arambaré, Camaquã, Canguçu, Chuvisca, Cristal, Encruzilhada do Sul, Santana da Boa Vista e São Lourenço do Sul (UFRGS, 2002). Os Municípios podem ser observados na figura 1.

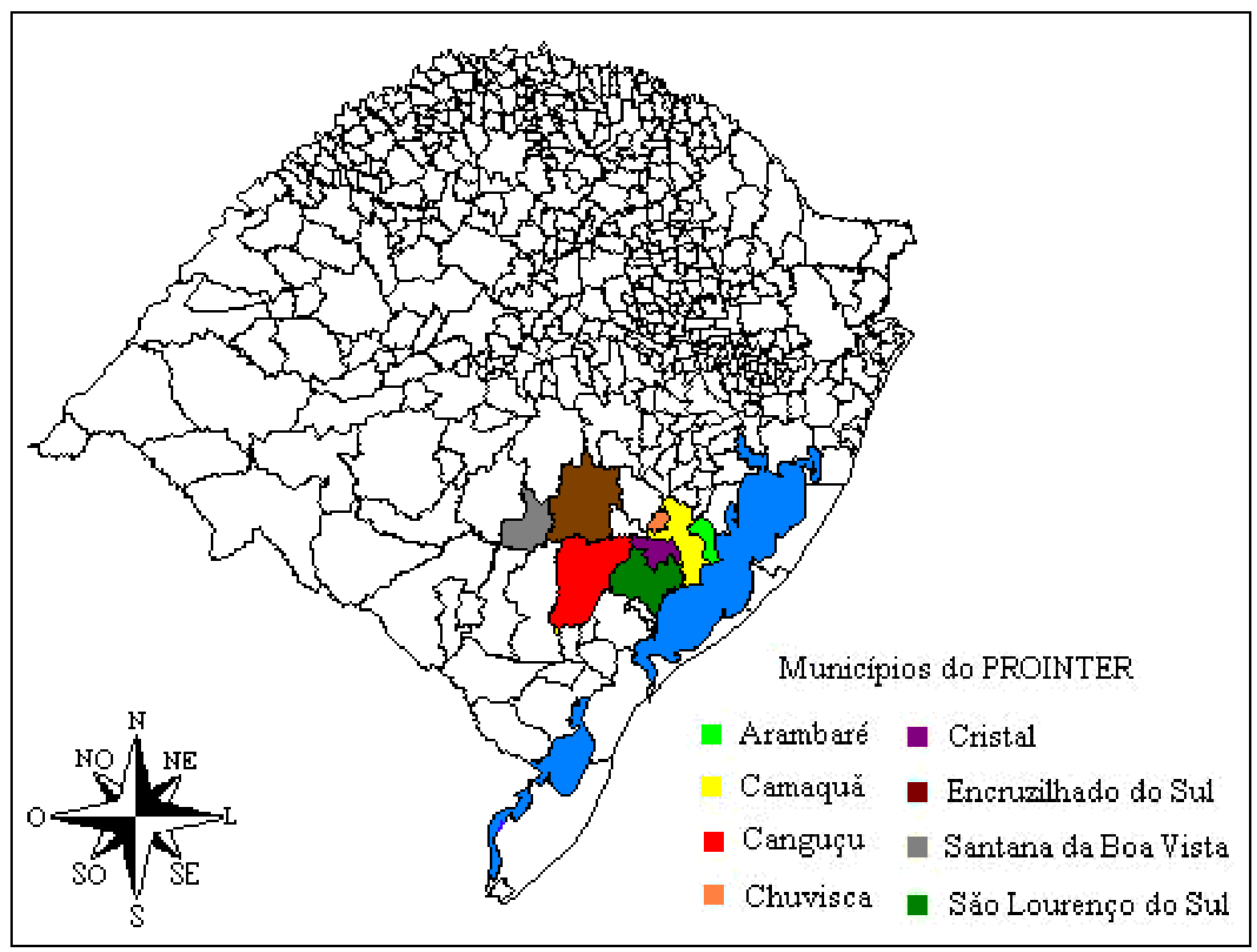

Figura 1 - Mapa dos oito Municípios pertencentes ao PROINTER - 2008 Fonte: Adaptada de UFRGS, 2002.

3 Termo popularizado nas últimas décadas, para designar a grande região localizada ao Sul do Rio Grande do Sul, a região é denominada também, por alguns, como região da campanha.

R. Inter. Interdisc. INTERthesis, Florianópolis, v.6, n.2, p. 191-209, jul./dez. 2009 
Para este estudo, em particular, a área empírica é o município de Santana da Boa Vista, que apresenta a maior população de idosos se comparada aos demais Municípios da área do PROINTER. Como mostra a tabela 1, o Município possui $14,9 \%$ de idosos (acima de 60 anos) em sua população, índice superior até mesmo à média do Estado do Rio Grande do Sul que é de 10,4\%.

\begin{tabular}{lccc}
\hline \hline \multicolumn{1}{c|}{ Municípios } & Idosos (n) & Idosos (\%) & Total geral (n) \\
\hline Chuvisca & 429 & 9,5 & 4.502 \\
Camaquã & 6.698 & 11,1 & 60.383 \\
Cristal & 796 & 12 & 6.632 \\
Arambaré & 513 & 13,1 & 3.917 \\
Encruzilhada do Sul & 3.174 & 13,3 & 23.906 \\
Canguçu & 6.924 & 13,6 & 51.447 \\
São Lourenço do Sul & 6.072 & 13,9 & 43.691 \\
Santana da Boa Vista & 1.293 & 14,9 & 8.691 \\
\hline Rio Grande do Sul & 1.065 .117 & 10,4 & 10.187 .841
\end{tabular}

Tabela 1 - Porcentagem de idosos nos Municípios pertencentes à área de estudo do PROINTER - 2008 Fonte: Instituto Brasileiro de Geografia e Estatística (IBGE, 2002), elaborada pela autora, 2008.

Outro fator de escolha foi à ausência de estudos aprofundados sobre o envelhecimento e a longevidade, tanto no município de Santana da Boa Vista como na área, como um todo.

Pode-se afirmar que esta discussão é relevante no debate atual porque o envelhecimento populacional é um fenômeno em ascensão, atingindo países desenvolvidos, em desenvolvimento e subdesenvolvidos, tanto em zonas rurais, como urbanas. O envelhecimento pode ser considerado, segundo Camarano (2004) como uma das transformações sociais mais importantes no País desde a metade do século passado.

R. Inter. Interdisc. INTERthesis, Florianópolis, v.6, n.2, p. 191-209, jul./dez. 2009 
Mas, salienta a autora que é preciso considerar que a idade traz vulnerabilidades, perdas de papéis sociais, agravamento de doenças crônicas e degenerativas, entre outras, que devem ser minimizadas por políticas públicas. Estas, por sua vez, necessitam levar em conta a heterogeneidade de tal processo, podendo ser diferenciadas por sexo, grupo social, cor, raça, localização geográfica. Nesse sentido é importante entender que desenvolvimento econômico, envelhecimento populacional e condições de vida da população idosa devem ser reconhecidos como processos inter-relacionados.

A preocupação com o envelhecimento não é algo novo, pelo contrário, a velhice é tida como uma preocupação da humanidade desde o início da civilização, mas é preciso deixar claro, no entanto, que o século XX marcou os grandes avanços da ciência do envelhecimento, fruto da tendência do crescimento do interesse nas pesquisas e estudos sobre este processo, que já se anunciava nos séculos anteriores (NETTO, 2006).

Porém, segundo Netto (2006, p. 2), durante mais de duas décadas, os estudos sobre envelhecimento ficaram restritos aos aspectos biológicos da velhice, houve grande dificuldade de introduzir novos temas na questão do envelhecimento, sendo que apenas recentemente passou-se a pensar esse fenômeno também como biossocial.

Admite-se hoje que a velhice não necessariamente é acompanhada por manifestações patológicas, embora sejam frequentes doenças nessa faixa etária. Assumem também, particular importância os problemas econômicos e sociais a que está submetida a maioria dos idosos. Nesse sentido, constata-se, que a melhoria das condições de vida de pessoas com idades mais avançadas, não está apenas ligada às questões de saúde, pelo contrário, são múltiplos os aspectos do processo de envelhecimento, que devem ser analisados, na compreensão do que se constitui o bemestar para essa faixa populacional.

Entre esses aspectos, destaca-se, aqui, o papel dos benefícios previdenciários que, segundo Camarano (2004, p. 8) têm levado a uma mudança de percepção em relação ao "ser idoso", possibilitando a esse uma maior autonomia, assim como novas conquistas e busca de satisfação, principalmente junto à família e à sociedade.

Buscou-se assim, para este estudo, entender como estão vivendo esses novos idosos, considerando não apenas as questões econômicas e de saúde, mas também as consequências sociais e laborais ligadas ao envelhecimento.

R. Inter. Interdisc. INTERthesis, Florianópolis, v.6, n.2, p. 191-209, jul./dez. 2009 
Mais especificamente, procurou-se estudar as mudanças que ocorreram, a partir do acesso de agricultores familiares à cobertura previdenciária, considerando que esses benefícios influenciam um novo papel do idoso, dentro da unidade familiar.

O presente estudo parte desta introdução e, na seqüência, apresenta a proposta metodológica desenvolvida, analisa as concepções e percepções dos idosos referentes às mudanças que ocorreram em suas vidas após o recebimento dos benefícios da previdência, finalmente apresenta as considerações finais.

\section{ESTRATÉGIAS METODOLÓGICAS}

Trata-se de um estudo exploratório e descritivo com coleta e análise qualitativa de dados. A coleta dos dados foi feita a partir de fontes documentais e entrevista semiestruturada, combinando perguntas abertas e fechadas. Para a análise dos dados optouse pelo conteúdo temático, baseado nos estudos de Minayo (1992). As análises consistiram em descobrir os núcleos de sentido que compunham as comunicações cuja presença ou frequência tinham significado para o objetivo visado, ou seja, a presença de determinados temas denotava valores de referência e modelos de comportamento. A escolha dos participantes foi intencional, representada por 30 idosos residentes na área rural do município de Santana da Boa Vista, beneficiários da previdência, que se apresentavam em boas condições para responderem a entrevista e estavam incluídos na categoria de "agricultores familiares" e não patronal.

Esta pesquisa foi aprovada pelo Comitê de Ética em Pesquisa da Universidade Federal do Rio Grande do Sul, pelo Parecer de número 2007826. Todos os idosos participantes assinaram o Termo de Consentimento Livre e Esclarecido.

Os resultados alcançados pelas entrevistas mostraram um número maior de homens entre os idosos, grande número de viúvas, baixa escolaridade e predomínio da cor branca. Em relação à situação econômica, constatou-se que a renda dos benefícios previdenciários contribui significativamente para a vida das famílias dos idosos entrevistados, assim como, possibilita a essas melhorias materiais nas condições de vida. Os problemas de saúde são basicamente doenças crônicas comuns ao envelhecimento, sendo que, as limitações geradas por elas estão geralmente ligadas à capacidade de continuarem trabalhando na atividade agrícola. A religiosidade está presente na vida de

R. Inter. Interdisc. INTERthesis, Florianópolis, v.6, n.2, p. 191-209, jul./dez. 2009 
todos os idosos e influencia suas relações sociais. As relações de vizinhança foram consideradas fundamentais aos entrevistados, manifestadas pela solidariedade e ajuda mútua.

\section{SER IDOSO NO MEIO RURAL DE SANTANA DA BOA VISTA: COM A PALAVRA OS PROTAGONISTAS}

Para a análise que se segue considerou-se o aporte conceitual da problemática e os dados constantes no relatório final do PROINTER (UFRGS, 2008), o qual destacou que as populações rurais da área em estudo (referente a municípios da Metade Sul do Rio Grande do Sul) são afetadas por processos diferenciados de geração de desigualdades que implicam uma relação dialética de empobrecimento e enriquecimento. Estes são percebidos como evolução nas condições de existência dos agricultores que não se reduzem a modificações de seu nível de renda ou de seu poder aquisitivo, mas envolvem uma variedade de outras dimensões de sua existência, tais como: grau de oportunidades e espaço de decisão; capacidade em formular projetos para si e para sua descendência, e a se projetarem no futuro; capacidade em se reproduzirem socialmente como indivíduos, entidades sociais com determinada organização, corpus de valores, identidade cultural; capacidade em se reproduzirem fisicamente (satisfação das necessidades básicas, saúde, composição demográfica); grau de satisfação em relação às suas condições de existência (UFRGS, 2008).

Sendo assim, as variações de nível de renda apenas se constituem como fatores que influenciam as variáveis acima, não definindo por si só o empobrecimento e o enriquecimento. Empobrecimento e enriquecimento segundo Gerhardt e Lopes (2008, p. 5) "são noções polissêmicas, multidimensionais, que demandam uma abordagem interdisciplinar".

O processo de geração de desigualdades coloca em jogo fatores e mecanismos de variada natureza (internos e externos; materiais e imateriais), que se impõem aos atores sociais na qualidade de "dados". Correspondem ao nível da realidade que se propõe chamar de condições de sua emergência. Mas esse processo não é apenas uma conseqüência direta e mecânica destas condições. Esta relação é mediatizada pela atuação dos atores sociais que reinterpretam e remanejam suas "condições", dando nascimento a uma nova realidade que se propõe chamar de "situação".

R. Inter. Interdisc. INTERthesis, Florianópolis, v.6, n.2, p. 191-209, jul./dez. 2009 
Nesse sentido, buscaram-se elementos reflexivos capazes de "dar conta" da diversidade de dinâmicas e atores envolvidos no tempo e no espaço, considerando a materialidade (sistemas e aspectos técnicos) e imaterialidade (as relações e o simbólico) (GERHARDT \& LOPES, 2008).

Segundo Reynaut (2006) o campo da "materialidade" compreende as relações físicas e biológicas que se dão no âmbito da atmosfera, pedosfera, hidrosfera e geoesfera e inclui o ser humano e suas ações. O campo da "imaterialidade" compreende as relações não-materiais que se dão no âmbito das representações mentais e das relações sociais e tem uma autonomia relativa em relação ao campo da materialidade.

Segundo Gerhardt e Lopes (2008, p. 6) "a representação de um campo híbrido permite a superação da dicotomia da abordagem isolada da Sociedade/Natureza pela ênfase na articulação entre os dois campos essenciais". As interfaces ambiente e sistema técnico são as interfaces de maior conteúdo material, enquanto as representações sociais, os saberes, apresentam maior conteúdo imaterial. As "interfaces" referem-se àquilo que ocorre no campo híbrido, "combinando lógicas e naturezas distintas, mas em constante interação" (GERHARDT \& LOPES, 2008, p. 6). A figura 2 permite uma melhor compreensão do que foi citado acima.

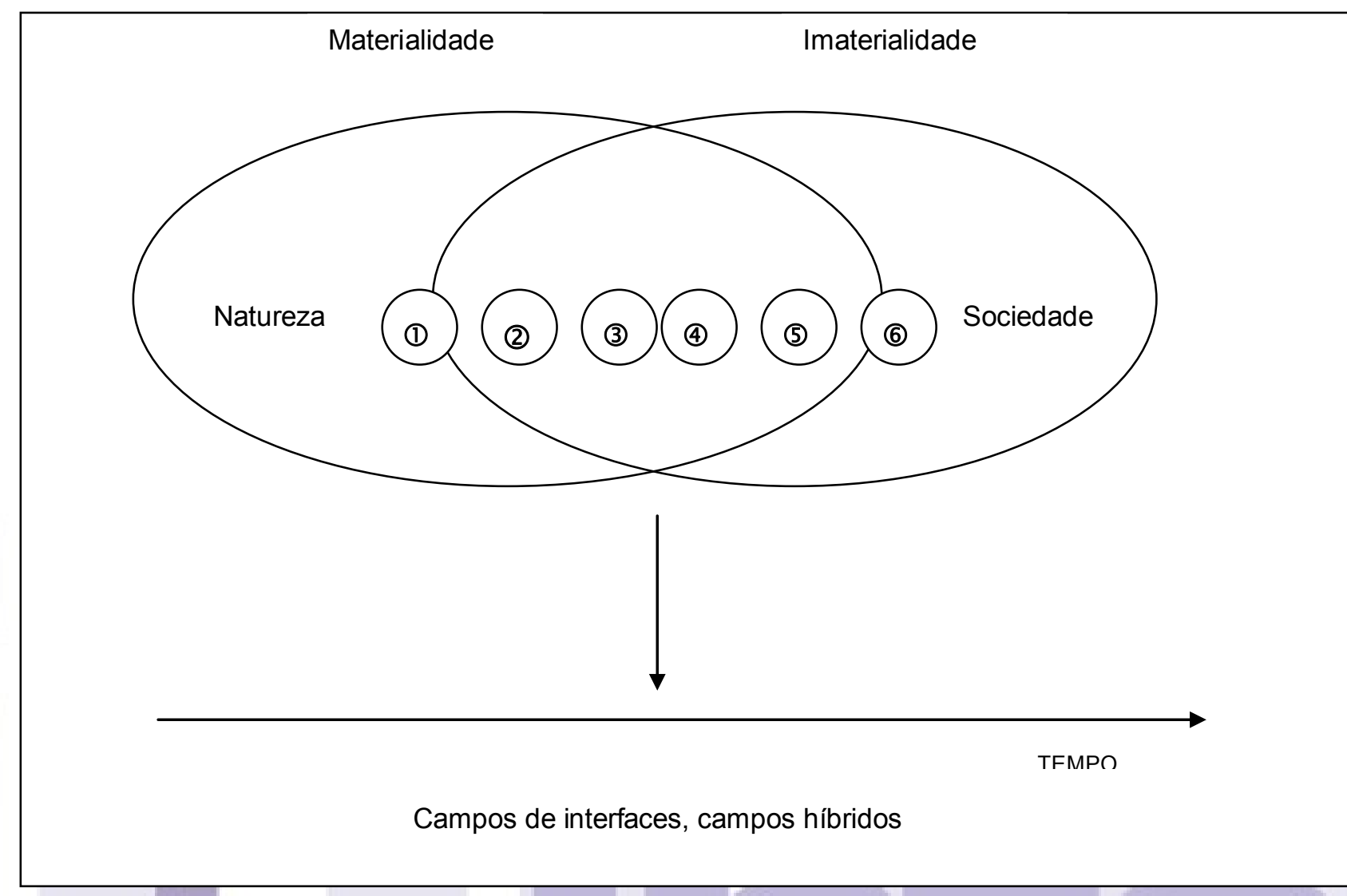

R. Inter. Interdisc. INTERthesis, Florianópolis, v.6, n.2, p. 191-209, jul./dez. 2009 


\section{Campos de Interfaces:}
(1) Ambiente
(2) Sistemas técnicos
(3) Saúde
(4) Política
(5) Educação e saberes
(6) Representações sociais

Figura 2 - Interação entre Sociedade/Natureza para compreensão de um campo híbrido Fonte: UFRGS, 2008, p. 22.

Dessa forma pensa-se que entender as mudanças ocorridas nas condições de vida da população de idosos rurais quando estes passaram a ter acesso aos benefícios previdenciários, não se limita apenas à abordagem material, mais especificamente, a uma análise do aumento dos "bens" materiais adquiridos após o recebimento dos benefícios previdenciários. Indo além, pensa-se que as condições de vida da população idosa em estudo é um assunto delas próprias, é uma sucessão de compromissos com a realidade em direção ao bem-estar (GERHARDT \& LOPES, 2008). Este bem-estar se está no imaterial, quando se observa que os idosos entrevistados citam sentimentos de alegria, pertencimento, satisfação em relação as suas condições de vida, mesmo dentre inúmeras limitações materiais.

Nessa perspectiva passou-se a analisar as mudanças na vida dos idosos rurais entrevistados em Santana da Boa Vista, a partir de suas concepções e percepções. Para tanto, foram feitas perguntas abertas a fim de que o idoso se sentisse à vontade para falar sobre sua vida, sobre o lugar onde morava e o que projetava para o futuro. Acredita-se que esse exercício reflexivo permitiu emergirem elementos para a compreensão dos efeitos da cobertura previdenciária na vida dos mesmos de forma mais complexa, considerando elementos objetivos e subjetivos, materiais e imateriais.

Alguns idosos entrevistados, ao serem perguntados sobre sua vida hoje comparada com a de antigamente, respondiam que "antigamente era melhor", isso devido ao fato de entenderem que as limitações físicas que aumentam com a idade, os impedem de fazer certos trabalhos que antes realizavam com maior facilidade. Essa dimensão de incapacidade relaciona-se ao valor atribuído a capacidade para o trabalho no meio rural,

R. Inter. Interdisc. INTERthesis, Florianópolis, v.6, n.2, p. 191-209, jul./dez. 2009 
alguns referiram que a vida era melhor "antigamente" quando podiam "dar conta" de todos os serviços, seja da casa e/ou da lavoura como pode ser observado nas falas seguintes:

Ué, agora eu me vejo cansada, eu vejo os serviços e não posso fazer, antes eu fazia de tudo, e com o maior prazer, coisa boa a lavoura, trabalhar, agora quando eu vejo os outros indo para a lavoura, gritando com os bois, lavrando, plantando, eu me sinto tão chateada, porque, até esta hortinha que tem aqui, eu plantava de máquina assim, não é qualquer mulher aqui em volta que planta de máquina e agora já é dois anos que eu tenho que pagar quem planta para mim (Mulher, 67 anos).

A vida hoje comparada com antigamente é diferente, porque antigamente eu era novo, trabalhava, já é bem diferente de quando vai chegando a idade (Homem, 63 anos).

Se alguns idosos (cinco dentre os trinta entrevistados) referiram que o passado foi melhor do que a vida presente, muitos (22 idosos), pelo contrário, falaram que sua vida estava melhor agora, tendo como referência as condições financeiras. Assim, pode-se concluir que as diferentes respostas são influenciadas pelos sentimentos que mobilizam o idoso, e pela referência predominante nos seus argumentos relacionados a esses.

Eu digo que está melhor porque eu trabalhava pior que bicho, era a coisa mais horrível do mundo e hoje me mantenho, só com a minha aposentadoria e dá para viver (Mulher, 73 anos).

Eu até considero melhor do que antigamente, antigamente a gente queria uma coisa e não podia né? Não podia comprar, não podia fazer, e agora mais ou menos o que precisa tem, graças a Deus (Homem, 72 anos).

Com o passado, hoje até que é melhor para a gente, a gente agora tem todos os confortos, porque quando a gente trabalhava às vezes nem de tudo a gente podia comprar para comer. Passava muitas vezes necessidade (Mulher, 75 anos).

Outros idosos, por sua vez (três), levaram em conta tanto o aspecto financeiro, quanto as condições físicas.

O passado é melhor porque a gente tem bastante saúde, mas em vista de negócio financeiro agora está melhor que antes, pois não se tinha condições de dinheiro (Homem, 66 anos).

A vida vai mudando porque a idade vai chegando. Mas melhorou porque agora a gente tem salário (Homem, 66 anos).

As falas analisadas mostram a relevância da cobertura previdenciária nas situações de vida dos idosos entrevistados em Santana da Boa Vista. Identifica-se que esses benefícios possibilitaram que muitos idosos diminuíssem sua "carga" de trabalho, pois agora têm acesso a uma renda regular (mês a mês) que, muitas vezes, é superior ao

R. Inter. Interdisc. INTERthesis, Florianópolis, v.6, n.2, p. 191-209, jul./dez. 2009 
que recebiam trabalhando na lavoura e que, em alguns casos, Ihes possibilita acesso a certos "confortos" que antes não cogitavam ter.

Nessa linha de estudo, Albuquerque, Lôbo e Raymundo (1999), ao entrevistarem 35 agricultores beneficiados pela Previdência Rural do município de Remígio - Paraíba observaram que para $82,9 \%$ deles a vida mudou para melhor depois que começaram a receber benefícios, enquanto para os demais a situação continuou a mesma. Dizem os autores que geralmente os mais idosos são os mais beneficiados. Esses, sem condições de continuar trabalhando, com a saúde fragilizada ainda mantêm em sua dependência filhos e netos, o que torna a sua vida difícil e carente.

O exemplo citado acima mostra uma realidade semelhante a dos idosos de Santana da Boa Vista. Constatou-se que quanto maior as limitações físicas que impedem ou dificultam continuar trabalhando, piores as condições financeiras, muitas vezes agravadas pela quantidade de filhos e netos que o idoso tem que ajudar, menor a satisfação com a vida, mesmo que eles recebam benefícios previdenciários.

No que diz respeito à vida no meio rural, os idosos manifestam o esforço desenvolvido para se manterem no lugar que desejam e com o qual possuem vínculos muito fortes:

\begin{abstract}
Sou apaixonada [pelo meio rural], nem sei quando eu ficar velha, enquanto eu puder dar um passo, e se eu achar mais tarde uma pessoa que me faça companhia, eu vou morrer aqui na campanha de tanto que eu gosto, nasci, me criei e nunca saí daqui (Mulher, 65 anos).
\end{abstract}

Ah gosto, eu tenho adoração por campanha, cidade eu acho que só quando eu morrer, porque não se sabe o que vai ser a vida da gente, mas enquanto eu puder viver aqui fora eu vou viver, se Deus quiser, eu tenho adoração por campanha, trabalhar com bicho, olhar para um bicho, olhar para outro (Homem, 63 anos).

$\mathrm{Na}$ cidade eu nunca me adaptei com aquele barulho, e a gente que arruma alguma coisinha trabalhando, têm amor as coisas da gente. Quero ficar aqui para poder conservar o campo que comprei com muita dificuldade, e para conservar tem que ficar aqui (Homem, 72 anos).

Com idade mais velha até que eu gostaria [de ir para cidade], mas agora não. Porque aqui eu posso fazer muita coisa, eu gosto da campanha, mas quando a gente estiver bem velho, é mais fácil na cidade pegar uma consulta, é mais perto (Mulher, 75 anos).

Observou-se nas entrevistas que o único motivo que faria com que os idosos saíssem do meio rural seriam as condições de saúde que poderiam impossibilitá-los de ficarem morando longe da sede do Município.

R. Inter. Interdisc. INTERthesis, Florianópolis, v.6, n.2, p. 191-209, jul./dez. 2009 
Nesse mesmo sentido, esses laços são observados em outra região do país como mostra Schwarzer (2000) ao inquirir idosos de Igarapé - Açú - Pará, também observou que há uma tendência desses permanecerem no seu local de residência, ao menos enquanto as condições de saúde o permitirem.

Assim, seja para "conservar o que foi construído com tanto esforço, ou pelo trabalho com a criação e com a terra, bem como pela liberdade que o ambiente rural proporciona, dificilmente os idosos deste estudo aceitariam morar na cidade, mesmo admitindo que a sede de Santana da Boa Vista é relativamente pequena e não apresenta tantos problemas de violência, poluição ambiental quanto nos grandes centros urbanos.

Observou-se, ao longo do estudo, que a vida dos idosos, juntamente com suas famílias é uma contínua construção de estratégias de sobrevivência para permanecerem no meio rural. Mesmo que muitos jovens tenham se mudado para cidades em busca de melhores oportunidades, os idosos permanecem, assim como alguns filhos e netos, que juntos, buscam, de alguma forma, se manterem no ambiente com o qual construíram laços culturais, patrimoniais e representa, por vezes, o investimento de toda uma vida.

Considerando que Santana da Boa Vista é um município "pobre", em uma região também "pobre", surpreende que a média de idosos desse município é muito superior à média do Estado (14,9\% e 10,4\% respectivamente). Esse dado levanta questionamentos já que se constatou entre os idosos entrevistados, que, muitas vezes, vivem em condições precárias, com pouco ou nenhum acesso a infraestrutura de moradia, à saúde e informação. Mesmo assim, mostram-se longevos e satisfeitos com suas condições de vida. Não é objetivo deste estudo entender especificamente os fatores que contribuem para a longevidade e a disparidade entre o Município em estudo e o Estado do Rio Grande do Sul, porém, ao afirmar que os benefícios previdenciários possibilitaram aos idosos entrevistados um aumento de seu bem-estar, admite-se que os mesmos podem ser elementos que influenciam para que vivam mais e melhor.

Patrício et al. (2008), ao analisarem a percepção dos próprios longevos em relação aos fatores contribuintes para sua longevidade e tendo como público 30 ex-ferroviários, residentes no município de Botucatu - São Paulo, observaram que esses consideram importante para viver mais e melhor: manter-se ativo, física e mentalmente e com pensamentos positivos; procurar ter um bom relacionamento social e familiar; ter renda para se sustentar; e crer na espiritualidade e na sorte. Mas, ainda segundo essas autoras,

R. Inter. Interdisc. INTERthesis, Florianópolis, v.6, n.2, p. 191-209, jul./dez. 2009 
o fato de entrevistarem idosos urbanos, fez com que esses falassem da aposentadoria como geradora de desestímulo à vida, ou seja, observaram o papel negativo da aposentadoria, percebendo que muitos morrem logo que se aposentam, porque tornaramse inativos e perdem as amizades e as relações sociais fica prejudicadas.

Por outro lado Cruz e Moriguchi (2002), ao estudarem o município gaúcho de Veranópolis, visto como um lugar onde os velhos são especialmente longevos e alegres, atribuíram essa realidade a um estilo de vida mais saudável. Entre outros fatores, afirmam que nesse município o nível de estresse é menor que em outras cidades por que a vida diária é "calma", uma vez que a cidade possui sua economia baseada na agricultura, mantendo muitos padrões socio-culturais que a classificam como uma cidade "rural". A atividade física é mais intensa, muitos trabalham ativamente desenvolvendo jardinagem, trabalho relacionado à agricultura e à terra. Por fim, mas não menos importante, os autores observaram que esses idosos convivem naturalmente com outras gerações, e destacam a importâncias dessas relações.

Tendo em conta os dois exemplos citados, um de idosos urbanos e outro rurais, pode-se concluir que ambos se assemelham em alguns aspectos, quais sejam; a importância de continuarem ativos e a participação social ativa com laços de amizade e família preservados.

Para os idosos de Santana da Boa Vista, conclui-se que esses fatores estão muito presentes em suas vidas e que a aposentadoria por idade no meio rural, diferente muitas vezes da urbana, possibilita ao idoso continuar trabalhando, assim como, manter suas relações, principalmente de vizinhança.

Relativamente ao vínculo entre vida e felicidade dentre os 30 idosos de Santana da Boa Vista 28 referiram que são felizes, e ao serem perguntados do motivo da felicidade responderam:

\begin{abstract}
Eu me sinto muito feliz, eu estou na minha casa, com saúde, tenho os meus bichinhos, tenho a minha casa, quando eu posso dar uma arrumada eu arrumo, quando eu não posso, eu não arrumo, faço uma horta, saio, dou uma caminhada, espaireço, coisa mais boa a vida no mato (Mulher, 66 anos).

Eu me considero feliz. Eu não me acho com problema de saúde que me atrapalha a vida, pois tem uns coitados, tem gente desenganada como tem aqui em Santana com uma saúde desta, eu tenho uns problemas de saúde, mas me considero feliz, eu tenho condições de caminhar, tenho condições de trabalhar e não tenho nada que me impeça a minha vivência, então eu me considero feliz (Homem, 67 anos).
\end{abstract}

R. Inter. Interdisc. INTERthesis, Florianópolis, v.6, n.2, p. 191-209, jul./dez. 2009 
Eu sou feliz com Jesus, muito feliz com Jesus, com as irmãs da igreja, com os irmãos da igreja, eles vem fazer culto na minha casa, orar comigo, cantar, louvor a Deus (Mulher, 67 anos).

Ué, já pensou que todos são amigos da gente, coisa mais boa, aqui também não falta nada graças a Deus, se eu quero comer eu como. Todo mundo, não tem uma pessoa que eu não gosto, que gosta de mim, eu não sei [risos] (Mulher, 62 anos).

Os motivos para a felicidade dos idosos em estudo são variados, alguns os relacionaram ao prazer de sentirem-se independentes; outros às boas condições de saúde, levando em conta a idade já avançada em que se encontram; também há os que a relacionaram às relações de vizinhanças e/ou à religiosidade. Porém, é na família que esses idosos encontram os maiores motivos de felicidade,

O que me torna feliz é estar junto com a família (Homem, 67 anos).

Me dou bem com todos, principalmente com os filhos e não tenho problema nenhum que está me prejudicando (Homem, 72 anos).

Ah! me sinto [feliz], graças a Deus. A minha felicidade foi ter criado todos os 9 filhos, todos trabalhando, com pouco estudo. As duas gurias e dois guris que têm mais de todos [estudo], mas os outros com pouco estudo todos eu ensinei trabalhar, graças a Deus, dos meus filhos não saiu nenhum maconheiro, não saiu nenhum bêbado, não saiu nenhum ladrão, então para mim foi uma grande vitória eu criar eles, estão todos trabalhando, se botarem eles em qualquer serviço eles sabem fazer, então para mim essa é a felicidade que eu tenho (Mulher, 61 anos).

Me sinto feliz, é que a gente tem agora aqui o que a gente precisa [dinheiro dos benefícios previdenciários], na época que a gente criou os filhos eu não tinha, passei trabalho para criar eles, agora, hoje eu tenho alguma coisa para ajudar os filhos, para mim me manter, eu acho que é uma felicidade que a gente pode ter ajudar os filhos (Mulher, 61 anos).

Essas manifestações de felicidade estão de acordo com estudo de Goldani (2004); ao analisar relações intergeracionais no Brasil, afirma que, perguntados sobre o que consideravam coisas boas em suas vidas, os idosos brasileiros apontaram a família, vista de diferentes formas, como o mais importante.

Nesse sentido, para Herédia e Sirena, (2006, p. 21) "a família é o espaço de 'promoção da felicidade', é o lugar da realização, é o espaço de promoção do bem-estar social, da construção da confiança, da autoestima e do equilíbrio pessoal". As autoras ainda afirmam que aqueles idosos que contam com a família enfrentam os problemas do envelhecimento de forma mais sutil, com aceitação e com reações mais positivas, expressos na vida cotidiana, como bom-humor, alegria e prazer.

R. Inter. Interdisc. INTERthesis, Florianópolis, v.6, n.2, p. 191-209, jul./dez. 2009 
Se a família é considerada como uma das coisas mais importantes na busca da felicidade na vida dos idosos brasileiros, deduz-se que, no rural e mais especificamente em Santana da Boa Vista esse fato é ainda mais presente. Observou-se que é a partir das estratégias de vida que se dão entre diferentes membros da família, que idosos, filhos e netos, tornam-se capazes de permanecerem no meio rural. Sendo assim, a importância atribuída à família vai além dos sentimentos de alegria, bom humor ou prazer, entrando na esfera do material, quando se observa que idosos "ajudam" filhos com alimentação e/ou dinheiro e filhos ajudam idosos, principalmente com trabalhos, que esses últimos já não são capazes de realizar.

Outro elemento analisado foi a posição de provedores que os idosos ocupam em muitas famílias, o que faz com que se sintam importantes e muitas vezes indispensáveis. Poder ajudar os filhos, vê-los felizes, serem valorizado pelas pessoas com quem convivem, faz com que esses idosos sintam prazer em continuar vivendo, assim como, vontade de continuar sonhando e planejando o futuro.

Assim, fazendo referência aos elementos materiais e imateriais que citamos no inicio destas reflexões, é possível a todos os indivíduos escolherem e definirem projetos de vida. As escolhas, no entanto, não se aplicam do mesmo modo e com a mesma intensidade; elas dependem da posição ocupada pelos membros da sociedade; dos desejos e aspirações pessoais, dos papéis desempenhados junto aos grupos de referência (a exemplo da família), do sentimento de pertencimento, dos reconhecimentos etc. Porém, segundo Almeida (1997), alicerçados em uma concepção de tempo rápido e alimentados por uma forte valorização do vigor e da força física, resta a certeza de que "há um tempo para os projetos de vida; tempo estranho aos idosos e bastante familiar aos jovens e adultos" (ALMEIDA, 1997, p. 102).

Mas a que sociedade estaria se referindo a autora, ao falar de um tempo "estranho" aos idosos e "familiar" aos jovens e adultos? Talvez às sociedades industriais que, muito frequentemente, são universalizadas por muitos autores, como se não existissem diferentes sociedades e que mudanças são diversas e complexas.

No Município em estudo, e aqui mais especificamente em relação aos idosos rurais entrevistados, dificilmente se diria que planejar o futuro é um tempo "estranho" aos idosos. Esses, assim como toda sua família que residem no meio rural, planejam juntos o

R. Inter. Interdisc. INTERthesis, Florianópolis, v.6, n.2, p. 191-209, jul./dez. 2009 
futuro e criam estratégias que os permitem permanecerem onde estão porque assim desejam. Ao serem perguntados se tinham planos para o futuro, os idosos responderam:

Ah, eu penso muita coisa enquanto eu puder dar um passo, arrumar, pintar minha casa, o que eu puder fazer, se eu puder. Se um dia desses Deus me ajudar vou comprar uma geladeira, se eu puder, se eu não puder, fazer o quê? (Mulher, 65 anos).

Eu sempre estou com planos de fazer coisas melhores, agora eu estou com planos de fazer horta, comprar mais um pedaço de terra, não sei, mas pode nem acontecer, mas é planos que eu penso (Mulher, 60 anos).

Eu tenho planos e se Deus quiser, eu vou conseguir, com a minha força e a força de Deus, quero deixar os filhos todos, pelo menos com uma casa como a mãe me deixou, tendo uma casa para morar o resto a gente faz. Para cada um, se Deus quiser, aí vai ser um sonho realizado (Mulher, 61 anos).

Tinha vontade de comprar nem que fosse 2 ha de terra para ter minha vaquinha, até vou botar meu dinheiro no juro para ver se eu junto mais um pouquinho para comprar (Mulher, 68 anos).

Seja para aumentar a propriedade ou para continuarem ajudando os filhos, mantem-se os projetos de futuro. Dentre todos entrevistados apenas uma idosa em más condições de saúde e com perdas familiares referiu ausência de projetos.

Como bem observado por Camarano (2004) a renda do benefício social, além de garantir a subsistência básica dos idosos, tem resultado na sua revalorização dentro da família, para a qual passou a ser um dos principais provedores, principalmente no contexto das estratégias materiais de sobrevivência das famílias pobres.

\section{CONSIDERAÇÕES FINAIS}

O envelhecimento populacional é um fenômeno em ascensão observado tanto em países desenvolvidos, como em desenvolvimento. Por esse motivo, aumenta o interesse de pesquisadores e promotores de políticas sociais, que buscam um maior entendimento sobre esse processo.

Considerou-se que para entender as mudanças ocorridas nas situações de vida da população de idosos rurais a partir do acesso aos benefícios previdenciários, é necessário ir além de uma abordagem material, dos "bens" materiais adquiridos após o recebimento desses benefícios. Por esse motivo, foram analisadas as concepções e percepções próprias dos idosos sobre essas mudanças.

R. Inter. Interdisc. INTERthesis, Florianópolis, v.6, n.2, p. 191-209, jul./dez. 2009 
Pode-se dizer que para se sentirem felizes e satisfeitos com suas vidas e continuarem planejando o futuro, os idosos entrevistados referem, além dos bens materiais, a satisfação pessoal que envolve uma série de outros valores "imateriais", dentre esses, destaca-se a importância que os idosos atribuem ao sentimento de pertencimento em relação à família e ao restante da sociedade, de se sentirem "úteis", poderem ajudar além de serem ajudados.

Sintetizando, aspectos materiais e imateriais "andam juntos", formando assim um campo híbrido de necessidade e conquistas. Pudemos observar que os benefícios previdenciários (pertencentes à esfera material) além de efetivamente permitirem acesso a bens e consumos, produzem elementos que influenciam nas representações de "poder" desses idosos (esfera imaterial), contribuindo com mudanças nas relações familiares, incluindo sentimentos de revalorização e permitindo continuarem a planejar o futuro.

R. Inter. Interdisc. INTERthesis, Florianópolis, v.6, n.2, p. 191-209, jul./dez. 2009 


\section{REFERÊNCIAS}

ALBUQUERQUE, F. J. B.; LÔBO, A. L. \& RAYMUNDO, J. da S. Análise das repercussões psicossociais decorrentes da concessão de benefícios rurais. Psicologia: Reflexão e Crítica, Porto Alegre, v.12, n. 2, 1999. Disponível em: $<$ http://www.cchla.ufpb.br/pospsi/drvs/producao artigos/1999An\%E1liseDasRepercPsicoD ecorrentesDaConcDeBenefRurais.pdf>. Acesso em: 10 dez. 2008.

ALMEIDA, V. L. V. de. Velhice e projeto de vida: possibilidades e desafios. In: CORTÊ, B.; MERCADENTE, E. F.; ACURI, I. G. (org.). Velhice, envelhecimento, complex(idade). São Paulo: Vetor Editora, 1997. p. $93-110$.

CAMARANO, A. A. (org.). Os novos idosos brasileiros: muito além dos 60 . Rio de Janeiro: IPEA, 2004.

CRUZ, I. B. M. da.; MORIGUCHI, E. H. (ed.) Projeto Veranópolis: reflexões sobre envelhecimento bem sucedido. Porto Alegre: Oficina da Longevidade, 2002.

GERHARDT, T. E.; LOPES, M. J. Desigualdades sociais e de saúde: elementos para análise interdisciplinar, 2008. Não publicado.

GOLDANI, A. M. Relações intergeracionais e reconstrução do estado de bem-estar. Por que se deve pensar essa relação para o Brasil? In: CAMARANO, A. A. (org.). Os novos idosos brasileiros: muito além dos 60. Rio de Janeiro: IPEA, 2004. p. 211-250.

HERÉDIA, V.; SIRENA N. Faces e interfaces da família no olhar dos idosos. Estudos Interdisciplinares sobre o Envelhecimento, Porto Alegre, v. 10, p. 09-27, 2006.

INSTITUTO BRASILEIRO DE GEOGRAFIA E ESTATÍSTICA - IBGE. Censo

Demográfico 2000 - agregado por setores censitários dos resultados do universo: Região Sul. Rio de Janeiro, v.4, 2002.

MINAYO, M. C. S. O desafio do conhecimento: pesquisa qualitativa em saúde. São Paulo: Hucitec, 1992.

NETTO, M. P. O estudo da velhice: histórico, definição do campo e termos básicos. In: FREITAS, E. V. et al. (org.). Tratado de geriatria e gerontologia. Rio de Janeiro: Guanabara Koogan, 2006. p. 2-12.

PATRÍCIO, K. P. et al. O segredo da longevidade segundo as percepções dos próprios longevos. Ciência \& Saúde Coletiva, Porto Alegre, v.13, n.4, p.1189-1198, jul/ago, 2008.

RAYNAUT, C. Interfaces entre a antropologia e a saúde: em busca de novas abordagens conceituais. Revista Gaúcha de Enfermagem, v. 27, n. 2, p. 149-165, 2006.

R. Inter. Interdisc. INTERthesis, Florianópolis, v.6, n.2, p. 191-209, jul./dez. 2009 
SCHWARZER, H. Impactos socioeconômicos do sistema de aposentadorias rurais no Brasil: evidências empíricas de um estudo de caso no Estado do Pará. Texto para Discussão (IPEA), n. 729, 2000.

UNIVERSIDADE FEDERAL DO RIO GRANDE DO SUL - UFRGS. Desenvolvimento rural na 'Metade Sul' do Rio Grande do Sul: sistemas de relações, mecanismos e dinâmicas sociais e naturais. 2008. Relatório técnico parcial. (Programa de PósGraduação em Desenvolvimento Rural) - Faculdade de Economia, Porto Alegre, 2008.

UNIVERSIDADE FEDERAL DO RIO GRANDE DO SUL - UFRGS. Evolução e diferenciação da agricultura, transformação do meio natural, e desenvolvimento sustentável em espaços rurais do sul do Brasil. 2005. Relatório técnico parcial.

(Programa de Pós-Graduação em Desenvolvimento Rural) - Faculdade de Economia, Porto Alegre, 2005.

UNIVERSIDADE FEDERAL DO RIO GRANDE DO SUL - UFRGS. Evolução e transformação da agricultura e desenvolvimento sustentável: contribuições para a elaboração de políticas públicas para a "Metade Sul" do Rio Grande do Sul. 2002.

Relatório técnico parcial. (Programa de Pós-Graduação em Desenvolvimento Rural) Faculdade de economia, Porto Alegre, 2002.

R. Inter. Interdisc. INTERthesis, Florianópolis, v.6, n.2, p. 191-209, jul./dez. 2009 